\title{
NOTAS SOBRE O ESTATUTO DA PESSOA COM DEFICIÊNCIA (LEI 13.146/2015) E A ALTERAÇÃO DA CURATELA E DO REGIME DE CAPACIDADE
}

Fábio Siebeneichler de Andrade*

Michelle Dias Bublitz**

SUMÁRIO: 1 Notas sobre a noção de pessoa e a concepção de capacidade; 2 Pessoa com deficiência: a busca por uma nomenclatura sistematizada e a promoção do conceito; 3 Convenção sobre os Direitos da Pessoa com Deficiência: a ressignificação dos institutos da igualdade e da autonomia; 4 Alterações do Código Civil pela Lei 13.146/2015 (Estatuto da Pessoa com Deficiência): repercussões; 5 Conclusão; Referências.

RESUMO: Aproximadamente $15 \%$ da população mundial convive com alguma deficiência. No Brasil, o censo IBGE 2010 revela que 23,9\% da população declarouse com alguma deficiência. Portanto, este segmento quantificado é diretamente afetado pelos efeitos dos fatos expostos no presente trabalho acadêmico. $\mathrm{O}$ estudo abaixo propõe uma análise a partir das alterações sofridas no regime jurídico das (in)capacidades e da curatela, no Brasil, após a promulgação da Lei 13.146, em 06 de julho de 2015. A Convenção sobre os Direitos da Pessoa com Deficiência alterou a significação da deficiência, o que impactou no reconhecimento da autonomia da pessoa com deficiência e, por consequência, nos institutos da capacidade e da curatela. Em 06 de março de 2015, promulgado o novo Código de Processo Civil, a ação de interdição sofre alterações importantes, especialmente, no que se refere aos limites da curatela. Além das alterações no instituto da curatela, institui o mecanismo de "tomada de decisão apoiada".

PALAVRAS-CHAVE: Pessoa com deficiência; Capacidade; Curatela.

\section{THE STATUTE OF PEOPLE WITH DEFICIENCY (LAW 13146/2015) AND CHANGE IN CARETAKING AND THE ABILITY REGIME}

ABSTRACT: Approximately 15\% of world population suffer from some sort of deficiency. The 1210 Census in Brazil has revealed that $23.9 \%$ of the population

\footnotetext{
* Doutor em Direito pela Universidade de Regensburg, Alemanha; Docente do Programa de Pós-Graduação em Direito (Doutorado e Mestrado) da Pontifícia Universidade Católica do Rio Grande do Sul (PUCRS), Brasil.

${ }^{* *}$ Bolsista CAPES; Doutoranda em Direito pela Pontifícia Universidade Católica do Rio Grande do Sul (PUCRS), Brasil; E-mail: michellebublitz@gmail.com
} 
confessed some type of deficiency. Such segment of the population is directly affected by facts which will be delineated in current analysis. Current analysis discusses changes in the juridical regime of (in)capacities and caretaking in Brazil posterior to Law 13146 of June 6, 2015. The Convention of the Rights of the Person with Deficiency changed the meaning of deficiency and impacted on the autonomy of the person with deficiency and, consequently, on capacity institutes and caretaking. The new Civil Code affects interdiction especially with regard to the limits of caretaking and introduces 'assisted decision-taking'.

KEY WORDS: People with deficiency; Capacity; Caretaking.

\section{APUNTES SOBRE EL ESTATUTO DE LA PERSONA DISCAPACITADA (LEY 13.146/2015) Y LA ALTERACIÓN DE LA TUTELA Y DEL REGIMEN DE CAPACIDAD}

RESUMEN: Aproximadamente un 15\% de la población mundial convive con alguna discapacidad. En Brasil, el censo del IBGE 2010 revela que el 23\% de la población se declaró con alguna discapacidad. Por lo tanto, este segmento cuantificado es directamente afectado por los efectos de los hechos expuestos en este trabajo académico. El estudio propone un análisis a partir de las alteraciones sufridas en el régimen jurídico de las (dis)capacidades y de la tutela, en Brasil, tras la promulgación de la Ley 13146, de 06 de julio de 2015. La convención sobre los Derechos de la Persona Discapacitada alteró significativamente el significado de la discapacidad, lo que ha impactado en el reconocimiento de la autonomía de la persona discapacitada y, por consecuencia, en los institutos de la capacidad y de la tutela. El 06 de marzo de 2015, promulgado el nuevo Código del Proceso Civil, la acción de interdicción sufre alteraciones importantes, especialmente, en lo que se refiere a los límites de la tutela. Además de las alteraciones en el instituto de la tutela, instituye el mecanismo de "toma de decisión apoyada".

PALABRAS-CLAVE: Persona discapacitada; Capacidad; Tutela.

\section{INTRODUÇÃO}

\subsection{NOTAS SOBRE A NOÇÃO DE PESSOA E A CONCEPÇÃO DE CAPACIDADE}

Pode soar como um truísmo a afirmação de que o conceito de pessoa constitui-se em noção central, nuclear, para o Direito. A origem do termo está 
umbilicalmente ligada às concepções greco-romanas: a palavra provém de uma máscara usada por atores, do que decorre a vinculação com a atuação do homem em um determinado cenário particular, no caso, o mundo jurídico ${ }^{01}$. Há que se ter presente, porém, que a prevalência do termo conecta-se à doutrina cristã, que ligou a pessoa à teoria do imago dei ${ }^{22}$, sendo reconhecido o êxito da noção no mundo medieval ${ }^{03}$.

O termo pessoa constitui, originariamente, um substrato da noção de ser humano, de caráter precipuamente biológico, para designar aquele que exerce uma determinada atividade na esfera jurídica, razão pela qual pode a ele ser atribuída a posição de sujeito de direito ${ }^{04}$. Observe-se que para designar aquilo que é exterior ao humano, desde o Direito romano conhece-se o termo res, coisa, que na linguagem jurídica designa os bens ${ }^{05}$.

Se, na sua gênese, poder-se-ia constatar um seccionamento entre as noções de pessoa e ser humano ${ }^{06}$, esta distinção não se configura em ordenamentos jurídicos contemporâneos: há identidade entre ser humano e pessoa.

A centralidade da noção de pessoa para o direito aponta que, decorre desta premissa, a circunstância de as normas jurídicas destinarem-se à regulação das relações sociais: estas, portanto, exigem a participação humana

A par do conceito de pessoa, faz-se menção à capacidade de direito, que configura a noção pelo qual se estabelece a condição de ser sujeito de direitos e obrigações na esfera jurídica. Passa-se, portanto, de uma noção em abstrato

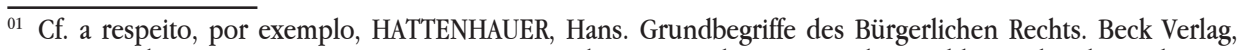
2000, 2. ed., p. 1 e segs; BIOY, Xavier. Le Concept de personne humaine en droit public: Recherche sur le sujet des droit fondamentaux. Dalloz, Paris, 2003, p. 42 e segs. SUPIOT, Alain, Homo Juridicus, Siglo XXI, 2007, p. 53 e segs.

${ }^{02}$ Para o tema da vinculação entre a noção de pessoa e a teoria da imagem de deus, ver, por exemplo, LOUREIRO, João Carlos, Pessoa, Dignidade e Cristianismo. In: Ars Ivdicandi: Estudos em homenagem ao Prof. Doutor Antônio Castanheira Neves. Coimbra, Coimbra, vol. I, p. 675 e segs.

${ }^{03}$ Pode-se, por exemplo, fazer menção à definição de Boécio que conceitua pessoa como uma substância individual de natureza racional. Sobre a contribuição medieval ao tema da pessoa e suas implicações teológicas e políticas, ver, por exemplo, ESPOSITO, Roberto. Le persone e le cose. Einaudi, 2014, p. 19, 21.

${ }^{04}$ Sobre o tema, ver, por exemplo, HATTENHAUER, Hans. Grundbegriffe des Bürgerlichen Rechts. 2. ed. Beck Verlag, 2000, p. 1 e segs; BIOY, Xavier. Le Concept de personne humaine en droit public: Recherche sur le sujet des droit fondamentaux, Dalloz, Paris, 2003, p. 42 e segs.; SUPIOT, Alain. Homo Juridicus, Siglo XXI, 2007 , p. 53 e segs.

${ }^{05}$ Para o sentido do termo res no direito romano e a relação entre pessoas e bens, ver, por exemplo, ESPOSITO, Roberto. Le persone e le cose, p. 38, 46, op. cit.

${ }^{06}$ É destacado pela doutrina que, originariamente, a noção de dignidade foi atribuída ao homem, sem qualquer referência ao termo pessoa, como se verifica na conhecida obra de Picco della Mirandola, Oratio de Hominis Dignitate. Sobre o tema ver, por exemplo, BIOY, Xavier, Le Concept de personne humaine em Droit Public, p. 53, op. cit. 
para a dinamicidade que contempla a possibilidade de atuar na esfera jurídica ${ }^{07}$. A capacidade jurídica se adquire, em princípio, para as pessoas naturais, com o nascimento e se extingue com a morte, o que denota, de um lado, a identidade entre essa noção e a existência biológica do ser humano, e, de outro, que ela se estende a todos na medida em que inexiste no ordenamento qualquer fundamento para a diferenciação entre as pessoas.

Em um segundo momento, cumpre pontuar a questão de que o vínculo jurídico, subcaso da relação social, decorre precipuamente de um ato de vontade, razão pela qual exige uma decisão racional daquele que se comunica com o outro do ponto de vista jurídico., a fim de constituir uma relação jurídica ${ }^{08}$.

Exemplo central a este respeito constitui-se o conceito de obrigação ( $o b$ ligatio), na qual uma parte se relaciona com o outra (devedor e credor) a fim de efetuar uma prestação, que em princípio se extingue somente com o cumprimento (solutio), ato pelo qual dar-se á a liberação do vínculo estabelecido.

Em face da obrigatoriedade que se configura para a pessoa a partir do vínculo estabelecido, há que se estruturar uma necessária construção jurídica para a necessária personificação do ser humano como centro de imputação de vínculos jurídicos. Trata-se de uma concepção normativista, expressando o que, na doutrina, foi reconhecido como a expressão marcante do pensamento jurídico do século XIX ${ }^{09}$.

Esta consiste na noção de capacidade de exercício, no sentido de que a pessoa deve ter as condições para exercer pessoalmente os direitos e obrigações na esfera jurídica. A primeira esfera de irradiação dessa definição abrange os menores, na medida em que esta categoria, por força da idade, merece uma tutela especial da ordem jurídica $^{10}$, na medida em que se reputa que ela ainda não possui o necessário discernimento para vincular-se juridicamente, em especial quanto aos atos de alienação.

Relativamente aos adultos, constitui-se a incapacidade em exceção, no sentido de que ela somente atinge aqueles que por determinadas razões médicas

\footnotetext{
${ }^{07}$ Nesse sentido, ver, por exemplo, ALPA, Guido/RESTA, Giorgio. Le Persone Fisique e i Diritti della Personalità. Utet, 2006, p. 16.

${ }^{08}$ Emblemática nesse sentido é a referência feita por Savigny: "Jedes Rechtsverhältnis besteht in der Beziehung einer Person zu einer anderer Rechtsperson" (Toda relação jurídica consiste na relação de uma pessoa com outra pessoa). System 11, $\S 60$, apud HATTENHAUER, H. Grundbegriffe des Bürgerlichen Rechts, p. 10, op. Cit.

${ }^{09}$ Ver, por exemplo, a este respeito, SCHMITT, Carl, Les Trois Types de pensée juridique, Puf, Paris, 2015, pg. 100 .

${ }^{10}$ A necessidade de proteção dos menores no que concerne a autonomia da vontade não implica que mereçam a devida consideração no que refere aos direitos da personalidade e o reconhecimento de sua liberdade. Sobre o tema, ver, por exemplo, GIL-ROSADO, Marie-Philomene. Les Libertés de l'esprit de l'enfant dans les rapports familiaux. Defrénois, 2006, pg. 7 e segs.
} 
não podem expressar sua vontade por força de ausência de discernimento. Esta foi a construção adotada pelo Código Civil brasileiro, no artigo $3^{\circ}$, incisos I a III, e que se altera com a regulamentação acerca das pessoas com deficiência.

\section{PESSOA COM DEFICIÊNCIA: A BUSCA POR UMA NOMENCLATURA SISTEMATIZADA E A PROMOÇÃO DO CONCEITO ${ }^{11}$}

A expressão "pessoa com deficiência" foi adotada oficialmente a partir da Convenção sobre os Direitos das Pessoas com Deficiência ${ }^{12} 13$ (Resolução n. 61/106), assinada, pela ONU, em 30 de março de 2007, a qual entrou em vigor em 03 de maio de 2008, eis que subscrita e ratificada pelo Brasil. Referida Convenção foi aprovada pelo Congresso Nacional brasileiro no dia 09 de julho de 2008 (Decreto Legislativo n. 186/2008) e, posteriormente, foi promulgada pela Presidência da República em 25 de agosto de 2009 (Decreto n. 6.949/2009). Em relação ao Brasil, trata-se do primeiro documento internacional de direitos humanos que adquiriu status de norma constitucional, uma vez que, nos termos do artigo $1^{\circ}$ do Decreto n. 6.949/2009, a referida Convenção foi aprovada nos moldes do parágrafo $2^{\circ}$ do artigo $5^{\circ}$ da Constituição Federal..$^{14}{ }^{15}{ }^{16}$ Pode-se afirmar, inclusive, que se trata do primeiro e único documento internacional de direitos humanos com caráter de Emenda Constitucional no Brasil, conforme estabelece o artigo $5^{\circ}$, parágrafo $3^{\circ}$, da

\footnotetext{
${ }^{11}$ Capítulo extraído parcialmente da obra de autoria individual da articulista: Pessoa com deficiência e teletrabalho: um olhar sob o viés da inclusão social: reflexões à luz do valor social do trabalho e da fraternidade. Porto Alegre: Livraria do Advogado, 2015. p. 17-22.

${ }^{12}$ BRASIL. Decreto 6.949, de 25 de agosto de 2009. Convenção sobre os Direitos das Pessoas com Deficiência e seu Protocolo Facultativo. Disponível em: < http://www.planalto.gov.br/ccivil_03/_ato2007 2010/2009/decreto/d6949.htm > . Acesso em: 14 jan. 2014.

13 Por razóes metodológicas, optou-se por não se proceder à análise de cada uma das previsões normativas da Convenção sobre os Direitos das Pessoas com Deficiência, eis que composta por 50 artigos, afora o seu Protocolo Facultativo, que inclui mais 18 disposições. A ênfase está direcionada para a análise do conteúdo de alguns dispositivos de suma importância no âmbito do sistema internacional de proteção dos direitos das pessoas com deficiência.

${ }^{14}$ Art. $5^{\circ}, \S 2^{\circ}$ Os direitos e garantias expressos nesta Constituição não excluem outros decorrentes do regime e dos princípios por ela adotados, ou dos tratados internacionais em que a República Federativa do Brasil seja parte. BRASIL. Constituição da República Federativa do Brasil de 1988. Disponível em: < http://www.planalto. gov.br/ccivil_03/constituicao/ConstituicaoCompilado.htm>. Acesso em: 14 jan. 2014.

${ }_{15}$ Para detalhes, ver: MAZZUOLI, Valério de Oliveira. Curso de direito internacional público. 3. ed. rev. atual. e ampl. São Paulo: RT, 2009. p. 768-776.

${ }^{16}$ Em específico, ver: MAZZUOLI, Valério de Oliveira. A tese da Supralegalidade dos Tratados de Direitos Humanos. Disponível em: $<$ http://ww3.lfg.com.br/publichtml/article.php?story $=20090403112247716 \&$ mode $=$ print\#1>. Acesso em: 04 fev. 2014.
} 
Constituição Federal. ${ }^{17} 1819$

Referida expressão veio a substituir outras, a saber: "pessoa portadora de deficiência"20 (presente em várias passagens da Constituição Federal de 1988, ${ }^{21}$ como por exemplo: art. $7^{\circ}$, inc. XXXI; art. 23, inc. II; art. 24, inc. XIV; art. 37, inc. VIII; art. 203, incs. IV e V; art. 227, § $2^{\circ}$, e art. 244, caput) e "portador de deficiência" (art. $40, \S 4^{\mathrm{o}}$, inc. I; art. 201, $\S 1^{\mathrm{o}}$; art. $227, \S 1^{\mathrm{o}}$, inc. II, da CF $/ 88$ ).

Há, todavia, nas palavras de Cibelle Linero Goldfarb, uma falha na expressão "portador de deficiência", na medida em que o termo "portador", ao mesmo tempo que enfatiza inicialmente a pessoa humana, sublinha como característica que tal porta (carrega, possui) uma deficiência, ${ }^{22}$ ou seja, poder-se-ia aqui exemplificar que a pessoa, caso fosse de seu interesse, optaria por sair de casa e deixar lá a deficiência, seja visual, física, intelectual, ou outra, como se objeto fosse, razão pela qual, a expressão "pessoas portadoras de deficiência" é bastante criticada pelo fato de que as deficiências não são "portadas" ou "carregadas" como um objeto. Logo, mesmo sendo a terminologia adotada pela norma constitucional, demonstrase que, ao utilizar o adjetivo "portador", o indivíduo traduz a deficiência como algo que a pessoa carrega consigo, valorizando mais esta posse, a deficiência, do que o possuidor, a pessoa.

${ }^{17}$ Art. $5^{\circ} \S 3^{\circ}$ Os tratados e convençóes internacionais sobre direitos humanos que forem aprovados, em cada Casa do Congresso Nacional, em dois turnos, por três quintos dos votos dos respectivos membros, serão equivalentes às emendas constitucionais. (Incluído pela Emenda Constitucional n. 45, de 2004). BRASIL. Constituição da República Federativa do Brasil de 1988. Disponível em: < http://www.planalto.gov.br/cci vil_03/ constituicao/ConstituicaoCompilado.htm > . Acesso em: 14 jan. 2014.

${ }^{18}$ Cf. texto disponível em: <http://www4.planalto.gov.br/legislacao/internacional/tratados-equivalentes-a-emend as-constitucionais-1>. Acesso em: 04 fev. 2014.

${ }^{19}$ Nas palavras de Luiz Alberto David Araujo: "Para o referido tratado de Direitos Humanos ter vigência interna, a nosso ver, pela forma própria como é aprovado, diferentemente dos tratados regulares, ele não necessitaria da promulgação do Presidente da República. Se o instrumento foi votado duas vezes, com quórum de três quintos, como se fosse o rito da emenda constitucional, parece que seria desnecessária a vontade do Presidente da República, pois o Congresso Nacional, em dois turnos, atingiu o elevado quórum, deixando clara a vontade do Brasil e incorporar tal tratado. E podemos nos servir, como parâmetro, do processo legislativo da emenda constitucional, que não tem a necessidade de sanção. Ela é promulgada pelas mesas das duas casa, conforme artigo 60, $\S 3^{\circ}$, da Constituição Federal". In. SEGALLA, Juliana Izar Soares da Fonseca; ARAUJO, Luiz Alberto David. A Utilização do Novo Conceito de Pessoa com Deficiência: Uma Advertência Necessária. Direitos Fundamentais \& Justiça, Porto Alegre: HS Editora, ano 6, n. 19, abr./jun 2012. p. 151

${ }^{20}$ Importante referir que até a promulgação da Emenda Constitucional n. 12, de outubro de 1978, a palavra empregada constitucionalmente era "excepcional" (art. 175, § 4 $4^{\circ}, \mathrm{CF} / 67$ com alterações dadas pela EC 1/69); a partir adotou-se a expressão "deficiente". Como se verá ao longo do capítulo, a expressão vigente na Constituição Federal de 1988 é "pessoas portadoras de deficiência".

${ }^{21}$ Mantiveram-se os textos constitucionais originais, quando transcritos, por uma questão didática. No entanto, entende-se que já houve modificação da terminologia diante da incorporação dos termos da Convenção sobre os Direitos das Pessoas com Deficiência. Assim, o correto seria já fazer constar o termo "pessoa com deficiência" no lugar de "pessoa portadora de deficiência".

${ }^{22}$ GOLDFARB, Cibelle Linero. Pessoas portadoras de deficiência e a relação de emprego: o sistema de cotas no Brasil. Curitiba: Juruá, 2009. p. 30. 
A expressão "pessoa portadora de deficiência" começa a ser questionada, momento em que se propõem, alternativamente, "sua substituição por portadores de necessidades especiais" ${ }^{\text {”3 }}$. Contudo, outra visão crítica é apontada, no sentido de que a expressão "pessoa com necessidades especiais" é gênero que contém as pessoas com deficiência, mas também acolhe os idosos, as gestantes, enfim, qualquer situação que implique tratamento diferenciado, ${ }^{24}$ além de, equivocadamente, continuar perpetuando a ideia de que as ditas "necessidades especiais" são portadas como se objeto fossem, não definindo o conteúdo distintivo de cada indivíduo. ${ }^{25}$ O adjetivo "especial", além de não projetar em si qualquer diferenciação, não se constitui numa característica exclusiva das pessoas com deficiência.

Novamente, a forma de tratamento passa a ser debatida, pois, "necessidades especiais" quem não as têm, com ou sem deficiência? ${ }^{26}$ Esclarece-se, a título de curiosidade, que essa terminologia estava relacionada às "necessidades educacionais especiais" de algumas crianças com deficiência, termo utilizado na área da Educação, e que passou a ser difundido para todas as circunstâncias, fora do ambiente escolar, sem o cuidado necessário. ${ }^{27}$

Inadequadamente, ainda hoje, utiliza-se a expressão "pessoas com necessidades especiais", demonstrando-se a tentativa da sociedade em evoluir, transformar o tratamento conferido, que foi numa visão linear da ideia de invalidez e incapacidade à tentativa de nominar a característica peculiar da pessoa sem estigmatizá-la. Nesse sentido, opta-se pelo referencial de Sassaki no sentido de que "o conceito de deficiência não pode ser confundido com o de incapacidade [...]. O conceito de incapacidade denota um estado negativo de funcionamento da pessoa, resultante do ambiente humano e físico inadequado ou inacessível, e não um tipo de condição" ${ }^{28}$

Aqui, necessário se faz destacar que se tem observado ainda nos dias de hoje a adoção de alguns eufemismos para qualificar a pessoa com deficiência,

${ }^{23}$ FIGUEIREDO, Guilherme José Purvin de (Coord.). Direitos da Pessoa Portadora de Deficiência. São Paulo: Max Limonard, 1997. Advocacia Pública \& Sociedade, ano I, n. 1, 1997, p. 47.

${ }^{24}$ FONSECA, Ricardo Tadeu Marques da. O trabalho da pessoa com deficiência: lapidação dos direitos humanos: o direito do trabalho, uma ação afirmativa. São Paulo: LTr, 2006. p. 136.

${ }^{25}$ FONSECA, Ricardo Tadeu Marques da. O trabalho da pessoa com deficiência: lapidação dos direitos humanos: o direito do trabalho, uma ação afirmativa. São Paulo: LTr, 2006. p. 136.

${ }^{26}$ RULLI NETO, Antonio. Direitos do portador de necessidades especiais: guia para o portador de deficiência e para o profissional do direito. 2. ed. São Paulo: Fiúza, 2002. p. 32. apud GOLDFARB, Cibelle Linero. Pessoas portadoras de deficiência e a relação de emprego: o sistema de cotas no Brasil. Curitiba: Juruá,2009. p. 31-32.

27 SILVA, Maria Isabel da. Por que a terminologia "pessoas com deficiência"? Disponível em: < http://www.s elursocial.org.br/pages/display/porque > . Acesso em: 18 abr. 2011.

28 SASSAKI, Romeu Kazumi. Atualizações semânticas na inclusão de pessoas: Deficiência mental ou intelectual? Doença ou transtorno mental? Revista Nacional de Reabilitação, ano IX, n. 43, mar./abr. 2005. 
com o objetivo de tentar justificar por meio destes a libertação de certos estigmas históricos ${ }^{29} \mathrm{e}$, assim, promover a valorização da pessoa humana. Otto Marques da Silva ${ }^{30}$ destaca algumas expressões aparentemente inofensivas ou descontraídas, que acabam por revelar a opinião das pessoas que as utilizam - velada, mas verdadeira - sobre as pessoas com deficiência, como: "aleijado", "defeituoso", "incapacitado", "inválido", "excepcional", ${ }^{11}$ "retardado", dentre outros; enfatizando a deficiência mais do que a pessoa. ${ }^{32}$

Luiz Alberto David Araujo ${ }^{33}$ afirma que a leitura desse rol leva a uma interpretação bastante variada da ideia que se tem desse grupo social. Algumas expressões ou palavras realçam a incapacidade, outras mais a noção de deficiência, outras não chegam sequer a mencionar o ponto fulcral da questão - a própria deficiência - ao usar de eufemismo para enfrentar a forma de tratamento que se quer conferir.

José Pastore chama a atenção para o fato de que as relações humanas

costumam ser formadas pela primeira impressão. E, nesse caso, chamam mais atenção os atributos (as deformidades) do que os portadores desses atributos (seres humanos). Em outras palavras, as deformidades vêm antes das pessoas. A partir daí compõe-se uma visão desumana e estereotipada das pessoas. ${ }^{34}$

Romeu Sassaki explicita que "jamais houve ou haverá um único termo correto [...]. A razão disto reside no fato de que a cada época são utilizados termos cujo significado seja compatível com os valores vigentes em cada sociedade [...]". 35 Mas, segundo o mesmo autor, o maior problema decorrente do uso de termos

${ }^{29}$ FONSECA, Ricardo Tadeu Maques da. O novo conceito constitucional de pessoa com deficiência: um ato de coragem. In. FERRAZ, Carolina Valença et al. Manual dos direitos da pessoa com deficiência. São Paulo: Saraiva, 2012. p. 22.

${ }^{30}$ SILVA, Otto Marques da. A epopeia ignorada: a pessoa deficiente na história do mundo de ontem e hoje. São Paulo: Centro São Camilo de Desenvolvimento em Administração da Saúde (CEDAS), 1986. p. 32.

${ }^{31}$ Nair Lemos Gonçalves, falecida em 10 de março de 2013, foi pioneira na luta pelos direitos das pessoas com deficiência. Cabe citar a obra: GONÇALVES, Nair Lemos. A pessoa excepcional e a legislação brasileira. Revista de informação legislativa, v. 14, n. 56, p. 125-138, out./dez. de 1977. Revista de direito do trabalho, v. 3, n. 13, p. 29-41, maio/jun. de 1978. Disponível em: < http://www2.senado.leg.br/bdsf/bitstream/handle / id/181038/000360866.pdf?sequence $=3>$. Acesso em: 26 mar. 2014.

${ }^{32}$ GOLDFARB, Cibelle Linero. Pessoas portadoras de deficiência e a relação de emprego: o sistema de cotas no Brasil. Curitiba: Juruá, 2009. p. 30

33 ARAUJO, Luiz Alberto David. A proteção constitucional das pessoas com deficiência. 4. ed. rev. ampl. e atual. Brasília: CORDE, 2011. Disponível em: < http://www.pessoacomdeficiencia.gov.br/app/sites/default/files /publicacoes/a-protecao-constitucional-das-pessoas-com-deficiencia_0.pdf>. Acesso em: 26 mar. 2014.

${ }^{34}$ PASTORE, José. Oportunidades de trabalho para portadores de deficiência. São Paulo: LTr, 2000. p. 22-23.

35 SASSAKI, Romeu Kazumi. Atualizações semânticas na inclusão de pessoas: Deficiência mental ou intelectual? Doença ou transtorno mental? Revista Nacional de Reabilitação, ano IX, n. 43, mar./abr. 2005. 
incorretos reside no fato de que os conceitos obsoletos, as ideias equivocadas e as informações inexatas possam ser, de forma inadvertida, reforçados e perpetuados. Ademais, o mesmo fato também pode ser responsável pela resistência contra a mudança de paradigmas que, no caso das pessoas com deficiência, passa, nos tempos atuais, da integração para a inclusão. ${ }^{36}$

Cumpre esclarecer que o presente texto utiliza e utilizará daqui por diante a expressão "pessoa com deficiência", ressalvadas as expressões legais que não cabe modificação ou textos doutrinários que não se permite alteração por deliberalidade, uma vez que se entende melhor adequada face aos motivos expostos pelo preâmbulo da Convenção sobre os Direitos da Pessoa com Deficiência, no sentido de que a deficiência é um conceito em evolução que resulta da interação entre indivíduo e as barreiras atitudinais e do ambiente, lastreado pela dimensão social de sustentabilidade. A expressão "pessoa com deficiência" valoriza a pessoa humana à frente de sua deficiência, restando evidente a observância ao princípio da dignidade da pessoa humana.

Encontrar a terminologia melhor adequada para designar um grupo de pessoas é de fundamental importância para sua proteção jurídica, pois também pela linguagem se revela ou se oculta o respeito ou a discriminação. Vale ainda ressaltar que o destaque que se procura conferir às terminologias em comento deriva do fato de que a questão semântica, sobretudo na seara dos direitos fundamentais, tem uma perspectiva de inegável valor. Dizer que as palavras são apenas palavras e não servem para modificar a realidade é uma inverdade, ainda mais quando de fácil assimilação passam para o jargão e o gosto popular, podendo gerar mais preconceitos e tornarem-se até ofensivas.

As expressões, reconhece-se, não são estáticas. Evoluem da mesma forma que a sociedade incorpora novas realidades e valores, a cada época, em relação aos agrupamentos que a compõem. A nomenclatura atribuída às pessoas com deficiência acaba por refletir a percepção social que a elas se empresta. Durante anos de história, esse tipo de vocabulário esteve interligado aos aspectos médicos, como consequência do modelo que imperava em relação à deficiência, por sorte já superado, vigendo na atualidade o modelo social da deficiência.

Os termos apresentados, portanto, se prestaram para um primeiro enfrentamento da questão, enlaçando alguns pontos por meio dos quais os leigos

${ }^{36}$ SASSAKI, Romeu Kazumi. Terminologia sobre deficiência na era da inclusão. Revista Nacional de Reabilitação, São Paulo, ano 5, n. 24, p. 6-9, jan./fev. 2002. 
entendem o que vem a ser deficiência. O problema terminológico, no entanto, não se encerra aqui. A ele será necessário voltar quando do estudo do conceito de deficiência. Conteúdo que se analisará no próximo item.

\section{CONVENÇÃO SOBRE OS DIREITOS DA PESSOA COM DEFICIÊNCIA: A RESSIGNIFICAÇÃO DOS INSTITUTOS DA IGUALDADE E DA AUTONOMIA}

Como referido acima, a Convenção sobre os Direitos da Pessoa com Deficiência foi subscrita e ratificada pelo Brasil com status de norma constitucional, uma vez que, nos termos do artigo $1^{\circ}$ do Decreto 6.949/2009, a referida Convenção foi aprovada nos moldes do parágrafo $2^{\circ}$ do artigo $5^{\circ}$ da Constituição Federal. Por oportuno, reitera-se, dada a importância do tema, que se trata do primeiro e único documento internacional de direitos humanos com caráter de Emenda Constitucional no Brasil, conforme estabelece o artigo $5^{\circ}$, parágrafo $3^{\circ}$, da Constituição Federal.

A Convenção sobre os Direitos da Pessoa com Deficiência abandona a compreensão da deficiência como um aspecto intrínseco à pessoa, para entendêla como uma limitação que se agrava pela interação dos impedimentos naturais com as barreiras sociais, institucionais e ambientais, excluindo ou dificultando a participação do sujeito no meio social. Nisso, afilia-se ao modelo social de abordagem da deficiência em oposição ao modelo médico. ${ }^{37}$

Assim, é posto em pauta o "modelo médico", baseado em classificações categoriais e em critérios estritamente médicos, assente em terminologias, conceitos e definições ancoradas em inferências causais relativas à deficiência e inerentes à pessoa, sem tomar em consideração os fatores externos ou ambientais. O problema estaria "no indivíduo". O entendimento nessa época é de que as pessoas com deficiência deveriam adaptar-se à sociedade se desejassem fazer parte desta. A ideia que imperava era a de que a sociedade era perfeita em si, que não precisaria fazer modificações ou adaptações em razão destas pessoas, eis que não contribuíam ao desenvolvimento da sociedade de forma alguma, afinal eram vistos como incapazes, diferentes, anormais. ${ }^{38}$

\footnotetext{
${ }^{37}$ MENEZES, Joyceane Bezerra de. O direito protetivo no Brasil após a convenção sobre a proteção da pessoa com deficiência: impactos do novo CPC e do estatuto da pessoa com deficiência. Civilistica.com. Rio de Janeiro, a. 4, n. 1, jan.-jun./2015. Disponível em: < file://C:/Users/15190051/Downloads/Menezes-civilistica.co m-a.4.n.1.2015.pdf > . Acesso em: 07 dez 2015.

${ }^{38}$ MADRUGA, Sidney. Pessoas com deficiência e direitos humanos: ótica da diferença e ações afirmativas. São Paulo: Saraiva, 2013. p. 60.
} 
O modelo médico da deficiência foi responsável, em grande parte, pela resistência da sociedade em aceitar a necessidade de mudar suas estruturas e atitudes para incluir em seu seio as pessoas com deficiência. Segundo Cláudia Werneck, ${ }^{39}$ o modelo médico tem relação com a homogeneidade porque trata a deficiência como um problema do indivíduo (e, no máximo, de sua família) que deve se esforçar para "se normalizar" perante os olhos da sociedade.

No "modelo social", pelo contrário, a deficiência é entendida como um problema criado pela sociedade. A deficiência não é um atributo da pessoa, mas uma consequência de um conjunto complexo de situações, das quais um número razoável são criadas pelo meio ambiente social. A introdução da classificação dos fatores ambientais, quer em termos de barreiras como de elementos facilitadores da participação social, assumem um papel relevante, dado que é premissa fundamental deste modelo o reconhecimento da influência do meio ambiente, como elemento facilitador ou como barreira, no desenvolvimento, funcionalidade, participação e interação pessoa-meio ambiente, afastando-se, assim, a pessoa com deficiência da perspectiva estritamente reabilitativa e de tratamento. O problema está "na sociedade", e não no indivíduo, este sim no centro de suas decisões. É o contexto social que gera a exclusão. A valoração do indivíduo como pessoa e a necessidade de sua inclusão social acercam o modelo social das premissas baseadas nos direitos fundamentais, sobretudo do princípio da dignidade da pessoa humana, ao considerar em primeiro plano o respeito à pessoa, seguida, quando necessário, de outras circunstâncias relacionadas propriamente com a sua deficiência, tal como a sua história clínica. ${ }^{40}$

Por esse prisma, claro que o

"problema" não é do surdo, que não entende o que está sendo dito na TV, e, sim, da emissora que não colocou a legenda (sistema closed-caption); o "problema" não é do cego que não consegue estudar e, sim, dos estabelecimentos de ensino que não publicam e nem adquirem computadores em braile e que também não habilitam seus professores na língua de libras; o "problema" não é do deficiente físico que não pode subir escada ou entrar num ônibus e, sim, do Estado que aprovou construções e veículos sem rampas ou elevadores de acesso. ${ }^{41}$

\footnotetext{
${ }_{39}$ WERNECK, Cláudia. Manual sobre Desenvolvimento Inclusivo. Rio de Janeiro: WVA, 2005. p. 33.

${ }^{40}$ MADRUGA, Sidney. Pessoas com deficiência e direitos humanos: ótica da diferença e ações afirmativas. São Paulo: Saraiva, 2013. p. 60.

${ }^{41}$ CRUZ, Álvaro Ricardo de Souza. O direito à diferença: as ações afirmativas como mecanismo de inclusão social de mulheres, negros, homossexuais e portadores de deficiência. Belo Horizonte: Del Rey, 2003. p. 132-133.
} 
Dando corpo a uma antiga aspiração do movimento internacional das pessoas com deficiência, a Organização Mundial da Saúde - OMS aprova a Classificação Internacional do Funcionamento, da Deficiência e da Saúde, doravante denominada como CIF. A CIF foi aprovada pela $54^{a}$ Assembleia Mundial de Saúde para utilização internacional em 22 de maio de 2001 (resolução WHA54.21) e propõe a integração do modelo médico e do modelo social de deficiência, tentando realizar uma síntese que ofereça uma imagem coerente das diferentes perspectivas sobre a saúde, sejam elas: biológicas, individuais ou sociais, permitindo a visualização da interação pessoameio ambiente (atividades e participação) e as características do meio ambiente físico e social (fatores contextuais - pessoais). O texto representa uma revisão da Classificação Internacional de Deficiências, Incapacidades e Limitações - ICIDH, publicada inicialmente pela OMS com caráter experimental em 1980.

Ainda que a CIF, no âmbito da família das Classificações Internacionais da OMS, seja referenciada como uma classificação dos estados de saúde e estados relacionados com a saúde, importa reter que o conceito de saúde, presente neste documento, é um conceito muito abrangente que se prende com os diferentes setores da vida, com a funcionalidade humana, com o bem-estar e com a qualidade de vida da pessoa. Um dos principais objetivos da OMS com este novo sistema de classificação foi a definição de uma linguagem comum e de um quadro que uniformizasse conceitos, metodologias e critérios, coerentes e consentâneos com os progressos científicos, tecnológicos e sociais mais relevantes neste domínio.

Retomando, a Convenção sobre os Direitos da Pessoa com Deficiência, no seu artigo primeiro, estabelece que é propósito fundamental promover, proteger e assegurar o exercício pleno e equitativo de todos os direitos humanos e liberdades fundamentais por todas as pessoas com deficiência e promover o respeito pela sua dignidade inerente. ${ }^{42}$ Em linhas gerais, visa a superação das barreiras externas, de modo a reabilitar a sociedade para que esta possa acolher a todas pessoas, administrando as suas diferenças e integrando a diversidade.

Por sua vez, quando enfrenta o direito de igualdade perante à lei, no artigo 12, reafirma a capacidade legal das pessoas com deficiência para todos os aspectos da vida, em igualdade de condições com as demais. Pretende lhes garantir

\footnotetext{
${ }_{42}$ BRASIL. Decreto 6.949, de 25 de agosto de 2009. Convenção sobre os Direitos das Pessoas com Deficiência e seu Protocolo Facultativo. Disponível em: < http://www.planalto.gov.br/ccivil_03/_ato2007 2010/2009/decreto/d6949.htm >. Acesso em: $07 \mathrm{dez} 2015$.
} 
a possibilidade de condução dos próprios interesses, no exercício de sua capacidade e de sua expressão, como consequência da autonomia ${ }^{43}$. ${ }^{44}$

Para o exercício pleno da capacidade legal, a Convenção sobre os Direitos da Pessoa com Deficiência estabeleceu que os Estados deverão promover mecanismos de apoio e salvaguardas, quando necessários. No Brasil, a curatela foi usada como o principal mecanismo de apoio, mas, com a promulgação do Estatuto da Pessoa com Deficiência (Lei 13.146, em 06 de julho de 2015), institui-se o mecanismo de "tomada de decisão apoiada", alterando substancialmente o Código Civil.

O principal contributo da Convenção está exatamente no reconhecimento da autonomia e da capacidade das pessoas com deficiência, em igualdade de condições com as demais, como pressupostos de sua dignidade e de sua participação na vida social, familiar, laboral, econômica e política.

\section{ALTERAÇÕES DO CÓdIGO CIVIL PELA LEI 13.146/2015 (ESTATUTO DA PESSOA COM DEFICIÊNCIA): REPERCUSSÕES}

Foi sancionada no dia 6 de julho e publicada no dia 7 de julho de 2015, a Lei 13.146/2015, que institui o Estatuto da Pessoa com Deficiência. A referida norma entrou em vigor 180 dias após sua publicação (vacatio legis regulado no artigo 127), ao final do mês de dezembro de 2015.

\footnotetext{
${ }^{43}$ A síntese analítica de Bodin de Moraes, resume a discussão filosófica acerca da autonomia: "Aristóteles, Epicuro, Santo Agostinho, Descartes, Kant, Sartre, Habermas, todos os grandes pensadores da Antiguidade aos nossos dias, constararam ser infrutífero discorrer sobre a vida humana sem examinar justamente aquilo que a faz humana, e como tal única, individual e singular: o poder sobre si mesmo." Ainda que se chancele uma liberdade de querer o (BODIN DE MORAES, Maria Celina. Na medida da pessoa humana. Estudos de direito civil constitucional. Rio de Janeiro: Renovar, 2010, p.183).

${ }^{44}$ Artigo 12. Reconhecimento igual perante a lei. 1. Os Estados Partes reafirmam que as pessoas com deficiência têm o direito de ser reconhecidas em qualquer lugar como pessoas perante a lei. 2.Os Estados Partes reconhecerão que as pessoas com deficiência gozam de capacidade legal em igualdade de condições com as demais pessoas em todos os aspectos da vida. 3.Os Estados Partes tomarão medidas apropriadas para prover o acesso de pessoas com deficiência ao apoio que necessitarem no exercício de sua capacidade legal. 4.Os Estados Partes assegurarão que todas as medidas relativas ao exercício da capacidade legal incluam salvaguardas apropriadas e efetivas para prevenir abusos, em conformidade com o direito internacional dos direitos humanos. Essas salvaguardas assegurarão que as medidas relativas ao exercício da capacidade legal respeitem os direitos, a vontade e as preferências da pessoa, sejam isentas de conflito de interesses e de influência indevida, sejam proporcionais e apropriadas às circunstâncias da pessoa, se apliquem pelo período mais curto possível e sejam submetidas à revisão regular por uma autoridade ou órgão judiciário competente, independente e imparcial. As salvaguardas serão proporcionais ao grau em que tais medidas afetarem os direitos e interesses da pessoa. 5.Os Estados Partes, sujeitos ao disposto neste Artigo, tomarão todas as medidas apropriadas e efetivas para assegurar às pessoas com deficiência o igual direito de possuir ou herdar bens, de controlar as próprias finanças e de ter igual acesso a empréstimos bancários, hipotecas e outras formas de crédito financeiro, e assegurarão que as pessoas com deficiência não sejam arbitrariamente destituídas de seus bens. BRASIL. Decreto 6.949, de 25 de agosto de 2009. Convenção sobre os Direitos das Pessoas com Deficiência e seu Protocolo Facultativo. Disponivel em: < http://www.planalto.gov.br/ccivil_03/ato20072010/2009/decreto/d6949.htm > . Acesso em: 07 dez 2015.
} 
Entre várias alterações, a nova legislação altera e revoga artigos do Código Civil (cita-se, arts. 114 a 116), acarretando mudanças estruturais e funcionais na clássica teoria das incapacidades, acima aludida, o que repercute diretamente nos institutos da interdição e da curatela.

A norma alterou também alguns artigos do Código Civil que foram revogados expressamente pelo novo CPC (cita-se, art. 1.072, Lei 13.105, de 16 de março de 2015).

No que concerne ao tema da capacidade, foram revogados todos os incisos do art. $3^{\circ}$ do Código Civil ${ }^{45}$. Também foi alterado o caput do comando, passando a estabelecer que "são absolutamente incapazes de exercer pessoalmente os atos da vida civil os menores de 16 anos".

Modificou-se, igualmente, a redação do artigo $4^{\circ}$, extraindo-se do dispositivo a menção existente até então no inciso II à redução de discernimento. Faz-se menção, atualmente, à causas, transitórias ou permanentes, que impeçam a manifestação de vontade (inciso III).

Observa-se, portanto, que não existe mais, no sistema privado brasileiro, pessoa absolutamente incapaz que seja maior de idade, o que se constitui em alteração profunda relativamente ao que foi exposto inicialmente.

Como consequência, não há mais o que se falar em ação de interdição absoluta no sistema civil pátrio, uma vez que os menores não são interditados. Todas as pessoas com deficiência, das quais tratava o comando anterior, passam a ser, em regra, plenamente capazes para o Direito Civil. Trata-se de modificação legislativa significativa, com o propósito de propiciar a plena inclusão social.

Nesse aspecto, merece destaque o artigo $6^{\circ}$ da Lei 13.146/2015, segundo o qual a deficiência não afeta a plena capacidade civil da pessoa, inclusive para, por exemplo: casar-se e constituir união estável; exercer direitos sexuais e reprodutivos; exercer o direito de decidir sobre o número de filhos e de ter acesso a informações adequadas sobre reprodução e planejamento familiar; conservar sua fertilidade, sendo vedada a esterilização compulsória; exercer o direito à família e à convivência familiar e comunitária; e exercer o direito à guarda, à tutela, à curatela e à adoção, como adotante ou adotando, em igualdade de oportunidades com as demais

$\overline{45}$ Art. 30 São absolutamente incapazes de exercer pessoalmente os atos da vida civil: I - os menores de dezesseis anos; II - os que, por enfermidade ou deficiência mental, não tiverem o necessário discernimento para a prática desses atos; III - os que, mesmo por causa transitória, não puderem exprimir sua vontade. BRASIL. Lei 10.406, de 10 de janeiro 2002. Institui o Código Civil. Disponível em: < http://www.planalto.gov.br/ccivil_03/ leis/2002/ L10406compilada.htm > . Acesso em: 23 fev 2016. 
pessoas. ${ }^{46}$ Por oportuno, menciona-se que, em casos específicos, tais pessoas podem ser tidas como relativamente incapazes partir do enquadramento no artigo $4^{\circ}$ do Código Civil ${ }^{47}$.

Verificadas as aludidas alterações, parece-nos que o sistema de incapacidades deixou de ter um modelo rígido, passando a ser mais flexível: abandona-se o pensamento normativista, para uma visão jurídica organizativa ${ }^{48}$, marcada pelo ideal igualitário, e pela visão da dignidade da pessoa humana ${ }^{49}$.

Contudo, ao invés de eliminar por completo os elementos do Código Civil que discriminavam as pessoas com deficiência para colocá-las em plena igualdade com as demais pessoas, o Estatuto optou por desfigurar o regime das incapacidades, na medida em que não instituiu um sistema dotado de plena operacionabilidade, a fim de regular todos os pontos concernentes à necessidade de vinculação da pessoa no tráfico negocial. Em essência, pode-se reputar que o Legislativo mirou no que viu - a discriminação - e acertou no que não viu - a necessidade de apoiar quem, com ou sem deficiência, precise de sustentação para exercer os atos formais da vida civil. $^{50}$

Conforme já exposto no presente trabalho, pela legislação anterior, a regra geral era associar automaticamente a deficiência à incapacidade. Entretanto, não há razão para restringir a capacidade jurídica de quem tenha uma deficiência que não limite o discernimento, o uso da razão; na medida em que o que importa para o exercício dos atos da vida civil é a capacidade da pessoa de entender o que faz e de comunicar sua vontade. Se alguém possui o discernimento reduzido por qualquer

\footnotetext{
${ }^{46}$ Art. 60 A deficiência não afeta a plena capacidade civil da pessoa, inclusive para: I - casar-se e constituir união estável; II - exercer direitos sexuais e reprodutivos; III - exercer o direito de decidir sobre o número de filhos e de ter acesso a informações adequadas sobre reprodução e planejamento familiar; IV - conservar sua fertilidade, sendo vedada a esterilização compulsória; V - exercer o direito à família e à convivência familiar e comunitária; e VI - exercer o direito à guarda, à tutela, à curatela e à adoção, como adotante ou adotando, em igualdade de oportunidades com as demais pessoas. BRASIL. Lei $n^{0} 13.146$, de 6 de julho de 2015. Institui a Lei Brasileira de Inclusão da Pessoa com Deficiência (Estatuto da Pessoa com Deficiência). Disponível em: < http://www.planalto.gov.br/ccivil_03/_Ato2015-2018/2015/Lei/L13146.htm>. Acesso em: 23 fev 2016.

${ }^{47}$ Art. $4^{\circ}$ São incapazes, relativamente a certos atos, ou à maneira de os exercer: (Vide Lei $n^{\circ} 13.146$, de 2015) I - os maiores de dezesseis e menores de dezoito anos; II - os ébrios habituais, os viciados em tóxicos, e os que, por deficiência mental, tenham o discernimento reduzido; (Vide Lei $\mathrm{n}^{0} 13.146$, de 2015) III - os excepcionais, sem desenvolvimento mental completo; (Vide Lei ${ }^{0} 13.146$, de 2015) IV - os pródigos. Parágrafo único. A capacidade dos índios será regulada por legislação especial. (Vide Lei nº 13.146, de 2015) BRASIL. Lei 10.406, de 10 de janeiro 2002. Institui o Código Civil. Disponível em: < http://www.planalto.gov.br/ccivil_03/leis/2002/ L10406compilada.htm>. Acesso em: 23 fev 2016.

${ }^{48}$ A respeito, ver SCHMITT, Carl, Les Trois Types de pensée juridique, op. cit, p. 98.

${ }^{49}$ Sobre o tema ver, por exemplo, SCHWAB, Dieter/Löhnig, Martin, Einführung in das Zivilrecht, C.F. Müller, 2012, pg. 48; SARLET, Ingo, Dignidade da Pessoa Humana e Direitos Fundamentais, Livraria do Advogado, 2012.

${ }^{50}$ Disponível em: < http://www12.senado.gov.br/publicacoes/estudos-legislativos/tipos-de-estudos/boletins-legis lativos/bol40 > . Acesso em: $07 \mathrm{dez} 2015$.
} 
causa, deve ter apoio para exercer esses atos. E, se a pessoa não se comunica, precisa que alguém a represente e cuide de seus interesses em seu nome.

Em relação à curatela, o Estatuto inova, mais uma vez, na medida em que admite, por força do artigo 84, parágrafo $1^{\circ}$, a interdição de pessoa capaz: "quando necessário, a pessoa com deficiência será submetida à curatela, conforme a lei”.

A curatela de pessoa capaz é algo inusitado na história e tradição do Direito brasileiro. A orientação do Estatuto é clara: mesmo com a curatela, não haverá uma pessoa incapaz. Logo, com a vigência da referida norma ter-se-á uma nova categoria de pessoas capazes: os capazes sob curatela.

No sistema atual, o curador representa os absolutamente incapazes e assiste os relativamente incapazes. Ou seja, com a vigência da Lei 13.146/2015, qual será a função do curador de pessoa capaz? O Estatuto não indica plenamente uma resposta a esta indagação. Duas são as possíveis leituras a este respeito: pela primeira, o deficiente sob curatela pratica pessoalmente os atos da vida civil. Esta leitura é equivocada, pois se assim fosse, por que haveria de se nomear um curador ao deficiente? Uma segunda leitura indica que o curador de pessoa capaz deverá representa-lo ou assisti-lo. Contudo o desafio é exatamente saber se o curador deverá representar o deficiente ou apenas assisti-lo, pois como se trata de pessoa capaz, não há no sistema uma resposta a essa pergunta. O artigo 85 do Estatuto não responde esta questão ${ }^{51}$.

Da leitura do texto, parece que caberá ao juiz definir se o curador do deficiente, que prossegue sendo capaz, deverá representa-lo ou assisti-lo. De qualquer forma, a limitação do artigo 85 é clara, ou seja, a curatela só incide em questões patrimoniais. Cabendo ao curador representar ou assistir o deficiente, qual é a consequência de o deficiente praticar o ato sem assistência ou representação? Em tese, pela boa técnica, a resposta seria: nenhuma, pois ele é pessoa capaz e o ato é válido. Contudo, essa resposta torna a curatela do deficiente inútil e não o protege como deveria. Afinal, se curatela há é em razão de uma necessidade. Assim, haverá aplicação analógica das disposições dos artigos 166, I e 171, I, bem como do artigo

\footnotetext{
${ }^{51}$ Art. 85. A curatela afetará tão somente os atos relacionados aos direitos de natureza patrimonial e negocial. § 10 A definição da curatela não alcança o direito ao próprio corpo, à sexualidade, ao matrimônio, à privacidade, à educação, à saúde, ao trabalho e ao voto. $\S 20$ A curatela constitui medida extraordinária, devendo constar da sentença as razões e motivações de sua definição, preservados os interesses do curatelado. §3o No caso de pessoa em situação de institucionalização, ao nomear curador, o juiz deve dar preferência a pessoa que tenha vínculo de natureza familiar, afetiva ou comunitária com o curatelado. BRASIL. Lei $\mathrm{n}^{\circ} 13.146$, de 6 de julho de 2015. Institui a Lei Brasileira de Inclusão da Pessoa com Deficiência (Estatuto da Pessoa com Deficiência). Disponível em: < http://www.planalto.gov.br/ccivil_03/_Ato2015-2018/2015/Lei/L13146.htm>. Acesso em: 23 fev 2016.
} 
310 aos deficientes capazes, sob curatela. Nessas hipóteses a vontade do deficiente capaz não será suficiente.

O Estatuto gera, ainda, um outro problema, ao alterar a atual redação do artigo 1.767 do Código Civil, suprimindo a menção à ausência de discernimento, presente no inciso I da redação anterior, para prever a curatela aos que não puderem exprimir a sua vontade em razão de causa transitória ou permanente (inciso I da redação atual).

A pergunta que surge é: se o deficiente puder exprimir sua vontade, mas tiver limitações, que tornem necessária a curatela - conforme previsão do artigo 84 do Estatuto - em qual hipótese do artigo 1.767 do Código Civil se enquadrará esta curatela? A resposta é nenhuma, pois a nova redação do artigo 1.767, com a vigência do Estatuto, não dialoga com a própria previsão do Estatuto de existência de curatela do deficiente. Vê-se, portanto, que padece a nova legislação de uma percepção operacional completa acerca dos diversos tópicos concernentes ao sistema de incapacidade e exercício negocial.

Outra pergunta a ser suscitada consiste em saber se a pessoa, por causa transitória ou permanente, não puder exprimir sua vontade, se o juiz, em sentença, deve declará-la relativamente incapaz, tendo o curador a mera função de assistente?

A resposta deveria ser negativa, mesmo sob o risco de verificar-se a contrariedade a texto expresso do Código Civil, pois a sistemática da assistência é inútil e não atende ao interesse do incapaz que estará impedido de praticar qualquer ato da vida civil. Pondera-se, aqui, a necessidade de ignorar a mudança legislativa, sob pena de se concluir pelo desamparo total de parte da população. Em sentido contrário, Atalá Correia entende que "caso o quadro legislativo não se altere, será razoável tolerar uma hibridização de institutos, para que se admita a existência de incapacidade relativa na qual o curador representa o incapaz, e não o assiste. Entendida a questão de maneira literal, a interdição de pessoas teria pouco significado prático". 52

Por fim, pondere-se que a vacatio legis do Estatuto é de 180 dias contados a partir da publicação (6 de julho de 2015) e a do novo CPC é de 1 ano (publicação em 17 de março de 2015). Verifica-se que a vida de alguns dispositivos do Código Civil com redação dada pelo Estatuto será breve.

${ }_{52}$ Disponível em: < http://www.conjur.com.br/2015-ago-03/direito-civil-atual-estatuto-pessoa-deficiencia-traz-inovacoes-duvidas $>$. Acesso em: $07 \mathrm{dez} 2015$. 


\section{CONCLUSÃO}

Do que foi exposto, há que se necessariamente afirmar que o Estatuto da Deficiência constitui-se em uma das mais significativas alterações legislativas do Direito Privado brasileiro.

Trata-se de uma legislação que modifica significativamente a concepção jurídica vinculada à noção de pessoa, na medida em que retifica a construção da capacidade de direito.

Pretendeu o legislador, ao menos, atenuar a vinculação entre a noção de pessoa, de capacidade e de discernimento, considerados como elementos indissociáveis para a relação jurídica, com a conseqüência de que a ausência do indispensável conhecimento da parte sobre o significado do conteúdo do ato conduz ao estabelecimento de uma patologia, a incapacidade.

Em essência, rompe-se com um esquema jurídico e mental - aqui no sentido de mentalidade - fundado em uma percepção oitocentista do vínculo jurídico, a fim de acolher a necessária concepção de igualdade, retirando do conceito de incapacidade a referência a quem não possui discernimento.

Contudo, em face do que foi sumariamente referido, pode-se indagar se as soluções do legislador brasileiro contidas no Estatuto da Deficiência não poderiam ter sido mais bem elaboradas, a fim de abranger de forma mais minuciosa a riqueza de situações relativas à temática tratada.

Houve efetivamente um avanço no sentido de propiciar a inclusão. Há que se debater, porém, se o legislador atentou para a necessária articulação entre os diversos institutos relacionados à incapacidade, em especial a construção da curatela.

Nesse sentido, essas linhas, longe de esgotarem as questões indicadas no texto, são um convite à reflexão. Pondera-se que a eventual correção de alguns dos eventuais equívocos indicados não se configura como um retrocesso na questão da inclusão. Trata-se, na verdade, da indispensável busca de uma melhor operacionalidade em uma matéria altamente funcional, que se constitui a garantia de plena autonomia - a pessoas com deficiência ou não - a quem tenha condições de exercer os atos da vida civil e apoio a quem eventualmente precise. 


\section{REFERÊNCIAS}

ALPA, Guido; RESTA, Giorgio. Le Persone Fisique e i Diritti della Personalità, Utet, 2006.

ARAUJO, Luiz Alberto David. A proteção constitucional das pessoas com deficiência. 4. ed. rev. ampl. e atual. Brasília: CORDE, 2011. Disponível em: < http:// www.pessoacomdeficiencia.gov.br/app/sites/default/files /publicacoes/a-protecaoconstitucional-das-pessoas-com-deficiencia_0.pdf > . Acesso em: 26 mar. 2014.

BIOY, Xavier. Le Concept de personne humaine en droit public: Recherche sur le sujet des droit fondamentaux. Dalloz: Paris, 2003.

BODIN DE MORAES, Maria Celina. Na medida da pessoa humana: estudos de direito civil constitucional. Rio de Janeiro: Renovar, 2010.

CRUZ, Álvaro Ricardo de Souza. O direito à diferença: as ações afirmativas como mecanismo de inclusão social de mulheres, negros, homossexuais e portadores de deficiência. Belo Horizonte: Del Rey, 2003.

ESPOSITO, Roberto. Le persone e le cose. Einaudi, 2014.

FIGUEIREDO, Guilherme José Purvin de (Coord.). Direitos da Pessoa Portadora de Deficiência. Advocacia Pública \& Sociedade, ano I, n. 1, 1997.

FONSECA, Ricardo Tadeu Marques da. O trabalho da pessoa com deficiência: lapidação dos direitos humanos: o direito do trabalho, uma ação afirmativa. São Paulo: LTr, 2006.

FONSECA, Ricardo Tadeu Maques da. O novo conceito constitucional de pessoa com deficiência: um ato de coragem. In. FERRAZ, Carolina Valença et al. Manual dos direitos da pessoa com deficiência. São Paulo: Saraiva, 2012.

GIL-ROSADO, Marie-Philomene, Les Libertés de l'esprit de l'enfant dans les rapports familiaux. Defrénois, 2006.

GOLDFARB, Cibelle Linero. Pessoas portadoras de deficiência e a relação de 
emprego: o sistema de cotas no Brasil. Curitiba: Juruá, 2009.

GONÇALVES, Nair Lemos. A pessoa excepcional e a legislação brasileira. Revista de informação legislativa, v. 14, n. 56, p. 125-138, out./dez. de 1977. Revista de direito do trabalho, v. 3, n. 13, p. 29-41, maio/jun. de 1978. Disponível em: < http://www2. senado.leg.br/bdsf/bitstream/handle /id/181038/000360866.pdf?sequence $=3>$. Acesso em: 26 mar. 2014.

HATTENHAUER, Hans, Grundbegriffe des Bürgerlichen Rechts, Beck Verlag,, 2000, $2 \mathrm{a}$ ed.

LOUREIRO, João Carlos, Pessoa, Dignidade e Cristianismo: in Ars Ivdicandi - Estudos em homenagem ao Prof. Doutor Antônio Castanheira Neves. Coimbra, Coimbra. vol. I.

MADRUGA, Sidney. Pessoas com deficiência e direitos humanos: ótica da diferença e ações afirmativas. São Paulo: Saraiva, 2013.

MAZZUOLI, Valério de Oliveira. Curso de direito internacional público. 3. ed. rev. atual. e ampl. São Paulo: RT, 2009.

MAZZUOLI, Valério de Oliveira. A tese da Supralegalidade dos Tratados de Direitos Humanos. Disponível em: < http://ww3.lfg.com.br/publichtml/article. php?story = 2009040311 2247716\&mode $=$ print $\# 1>$. Acesso em: 04 fev. 2014 .

MENEZES, Joyceane Bezerra de. O direito protetivo no Brasil após a convenção sobre a proteção da pessoa com deficiência: impactos do novo CPC e do estatuto da pessoa com deficiência. Civilistica.com. Rio de Janeiro, a. 4, n. 1, jan.-jun./2015. Disponível em: <file:///C:/Users/15190051/Downloads/Menezes-civilistica.co m-a.4.n.1.2015.pdf > . Acesso em: 07 dez 2015 .

PASTORE, José. Oportunidades de trabalho para portadores de deficiência. São Paulo: LTr, 2000.

RULLI NETO, Antonio. Direitos do portador de necessidades especiais: guia para o portador de deficiência e para o profissional do direito. 2. ed. São Paulo: Fiúza, 2002. 
SARLET, Ingo, Dignidade da Pessoa Humana e Direitos Fundamentais, Livraria do Advogado, 2012.

SASSAKI, Romeu Kazumi. Terminologia sobre deficiência na era da inclusão. Revista Nacional de Reabilitação, São Paulo, ano 5, n. 24, p. 6-9, jan./fev. 2002.

SASSAKI, Romeu Kazumi. Atualizações semânticas na inclusão de pessoas: Deficiência mental ou intelectual? Doença ou transtorno mental? Revista Nacional de Reabilitação, ano IX, n. 43, mar./abr. 2005.

SCHMITT, Carl, Les Trois Types de pensée juridique, Puf, Paris, 2015.

SCHWAB, Dieter/Löhnig, Martin, Einführung in das Zivilrecht, C.F. Müller, 2012.

SEGALLA, Juliana Izar Soares da Fonseca; ARAUJO, Luiz Alberto David. A Utilização do Novo Conceito de Pessoa com Deficiência: Uma Advertência Necessária. Direitos Fundamentais \& Justiça, Porto Alegre: HS Editora, ano 6, n. 19, abr./jun 2012.

SILVA, Maria Isabel da. Por que a terminologia "pessoas com deficiência"? Disponível em: <http://www.s elursocial.org.br/pages/display/porque > Acesso em: 18 abr. 2011.

SILVA, Otto Marques da. A epopeia ignorada: a pessoa deficiente na história do mundo de ontem e hoje. São Paulo: Centro São Camilo de Desenvolvimento em Administração da Saúde (CEDAS), 1986.

SUPIOT, Alain, Homo Juridicus. Siglo XXI, 2007.

WERNECK, Cláudia. Manual sobre Desenvolvimento Inclusivo. Rio de Janeiro: WVA, 2005.

Recebido em: 29 de fevereiro de 2016 Aceito em: 06 de junbo de 2016 